\title{
O CURSO DE ARTES VISUAIS DO PARFOR- UNEB: BREVES NOTAS SOBRE A IMPORTÂNCIA DAS POLÍTICAS EDUCATIVAS PARTICIPATIVAS
}

\author{
Isa Maria Faria Trigo
}

\begin{abstract}
Resumo
Este ensaio pretende analisar alguns dos caminhos percorridos pelos programas de formação de professores da educação básica oferecidos pela Universidade do Estado da Bahia, desde os anos de 1990. Abordam-se três grandes programas: o Programa Intensivo de Graduação (Rede UNEB 200o), o Programa de Formação de Professores do Estado (PROESP) e, desde 2010, o Plano Nacional de Formação de Professores da Educação Básica, também designado Plataforma Paulo Freire (PARFOR). Analisando de forma mas aprofundada este último, o artigo constitui uma tentativa de descrever as estratégias de resistência dos grupos de trabalho, face à implementação do programa, evidenciando como as soluções criativas podem emergir a partir da dificuldades e impasses dos processos. Neste sentido, os lugares de tensão e de incompletude podem ser meios de transformação e de evolução, tanto no plano das práticas, como das tomadas de decisão políticas. O texto argumenta, finalmente, que as políticas foram obrigadas, no decurso deste processo, a responder às exigências e realidades das populações e instituições envolvidas.
\end{abstract}

\section{PaLAVRas-Chave}

Políticas educativas; Plataforma Paulo Freire; formação de professores; artes; currículo

\section{INTRODUÇÃO}

Nas últimas décadas o Brasil tem conhecido políticas para a ciência e o conhecimento que se continuam a deparar com as profundas diferenças e desigualdades que caraterizam o país. Neste contexto, consideramos que o reforço dos programas de pós-graduação, assim como os investimentos realizados na formação de investigadores doutorados e pós-doutorados merecem ser perspetivados atendendo a outros focos de atenção que implicam os níveis básicos da educação pública, também objeto de políticas específicas, tal como é a implementação do curso de Artes Visuais na PARFOR da Universidade do Estado da Bahia - UNEB, também conhecido como Plataforma Paulo Freire.

Constituiu objetivo deste programa assegurar o acesso a formação de nível superior a professores que já trabalhavam na rede pública, especialmente aqueles que habitavam em zonas mais remotas da região e que estavam a lecionar sem o nível de qualificação exigido por lei.

Neste texto intenta-se especificar fases desse processo, destacando alguns dos principais traços das estratégias levadas a cabo para solucionar vários impasses que surgiram durante o processo. Com efeito, assinala-se o facto de serem estratégias que resultam da própria experiência acumulada da instituição em programas estaduais de 
graduação desenvolvidos nos mais longínquos rincões do Estado da Bahia. Deste modo, o texto descreve o processo de implementação do programa PARFOR de Artes Visuais na UNEB, assim como algumas ações desenvolvidas para resolver as dificuldades que sugiram nesse percurso. Contempla, ainda, algumas informações que mostram o interesse e a pertinência em contar com a participação dos atores individuais e das comunidades locais no desenvolvimento de estratégias em prol da educação e da cultura, essencialmente em contextos como estes - marcados por desigualdades territoriais e de recursos.

\section{A INTERIORIZAÇÃo DA UNIVERSIDADE DO ESTADO DA BAHIA: POLÍTICAS, DIFICULDADES F SOLUÇÕES}

A universidade do Estado da Bahia (UNEB) surgiu em 1983, na base de uma configuração inicial composta pelo Centro Técnico da Bahia - CETEBA - e outras unidades (centros universitários, instituições e núcleos do interior) criadas pelo governo do Estado. Desde a sua criação, a universidade deu origem a faculdades - ou núcleos universitários - em diversas localidades. Trata-se de um processo que envolveu diversas negociações, marcadas por desigualdades de poder entre os atores envolvidos. Não esqueçamos, ainda, o facto de se tratar de um processo que, na sua origem, sofreu debilidades várias, nomeadamente a respeito das próprias condições de manutenção e existência de planeamento a médio e a longo prazo. Esta foi a tónica das quatro primeiras administrações. Entre 2006 e 2013, foi suspensa a criação de polos e de departamentos. No momento atual, a UNEB conta com 24 campi e 29 departamentos. Estes últimos correspondem às estruturas que, noutras universidades, são denominadas "faculdades".

Desde cedo, as unidades do polo da UNEB enfrentaram problemas de comunicação e de manutenção (em relação a imóveis, ao material permanente e de consumo, incluindo dificuldade de comunicação e de acesso à administração central, em Salvador) e de fixação dos docentes nos seus territórios. Trata-se de problemas pouco visados durante as sucessivas gestões de reitores e de governos estaduais, devido quer ao insuficiente aporte de verbas, quer à não priorização governamental do Estado da Bahia- o Estado ao qual pertence a universidade. Com efeito, duas gestões após a sua fundação, a universidade passou a ser administrada por reitores e diretores eleitos, enfrentando uma política inicial de interiorização pouco planeada, sem garantias de qualidade física e académica suficientemente ajustada para responder a um padrão de universidade expectável nos moldes adotados pelas agências de financiamento. Nesse contexto, os problemas de orçamento tem-se vindo a acumular desde longa data. É certo que com o aumento da procura, as necessidades também se avolumam. Contudo, o poder estadual não investe nos recursos, de forma proporcional.

Não podendo atrair recursos e projetos baseados na competência em investigação, que ainda é inferior às suas necessidades, e como universidade enorme e dispersa no território que é, a UNEB assentou a sua ação na resposta às necessidades mais urgentes do Estado da Bahia. Estas traduziram-se na formação de professores para o ensino, em geral. No mapa abaixo, destacam-se as cidades onde se situam os campi da UNEB. 


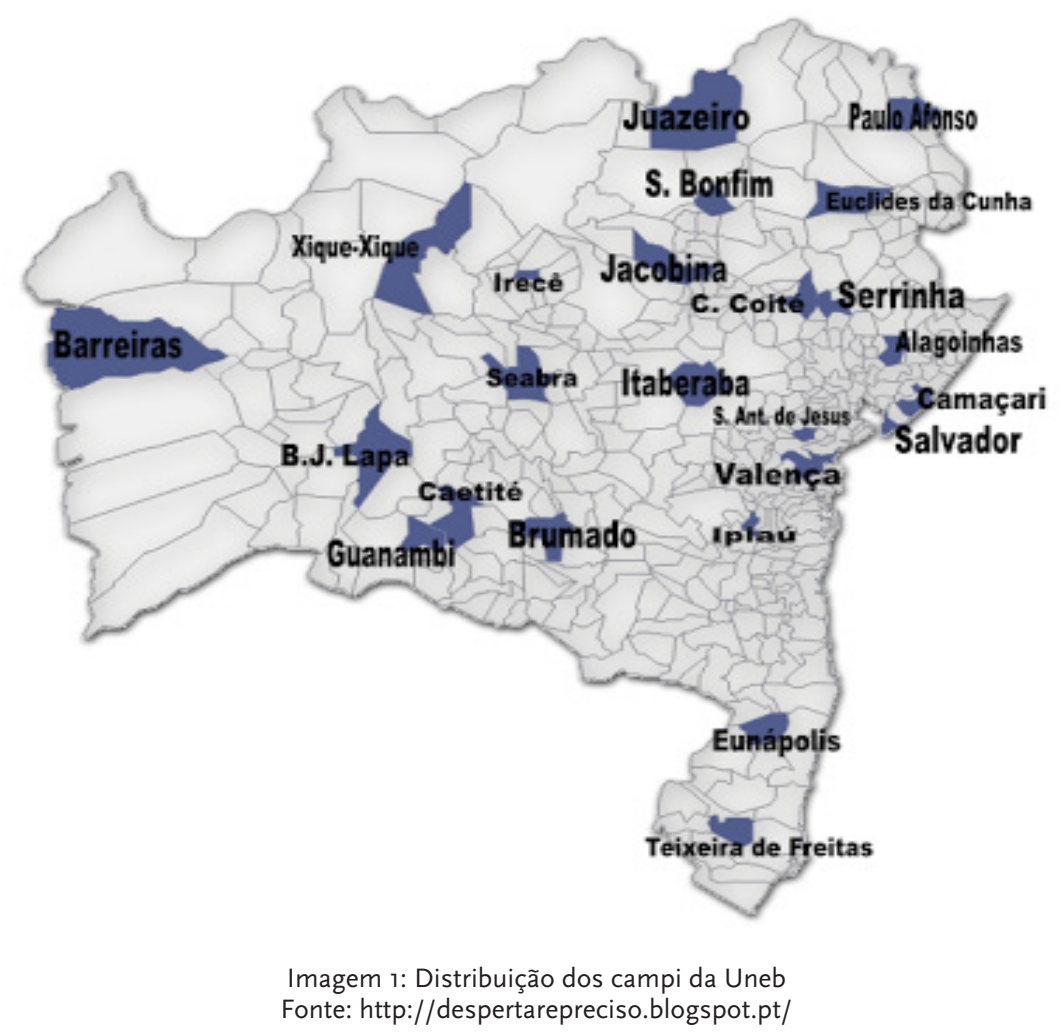

A seguir, apresentamos os Campi da UNEB, por ordem cronológica da sua criação:

- Salvador-Campus I

- Alagoinhas - Campus II

- Juazeiro - Campus III

- Jacobina - Campus IV

- Santo Antônio de Jesus -,,70'j Campus V

- Caetité - Campus VI

- Senhor do Bonfim - Campus VII

- Paulo Afonso - Campus VIII

- Barreiras - Campus IX

- Teixeira de Freitas - Campus X

- Serrinha - Campus XI

- Guanambi - Campus XII

- Itaberaba - Campus XIII

- Conceição do Coité - Campus XIV

- Valença - Campus xv

- Irecê - Campus xvi

- Bom Jesus da Lapa - Campus xvii

- Eunápolis - Campus xviii

- Camaçari - Campus xix

- Brumado - Campus xx 
- Ipiaú - Campus xxi

- $\quad$ Euclides da Cunha - campus xxii

- Seabra - Campus xxiii

- Xique-Xique - Campus XXIV

A UNEB sofreu com a aprovação sem emendas da Lei Estadual n. ${ }^{\circ} 7176$, de 10 de setembro de 1997 (Governo do Estado da Bahia, 1997). Esta lei limitou e retirou da instituição a sua parca autonomia para a execução dos recursos, reduzindo os seus cargos e modificando para pior a sua estrutura administrativa e académica'. No que diz respeito à gestão dos grandes desafios que a UNEB tem vindo a enfrentar nesses 32 anos de existência, talvez o mais complexo seja o da dificuldade de fixação do corpo docente nas unidades do interior, dada a distância e a falta de opções académicas, culturais e outras nas cidades pequenas.

A difícil manutenção das condições físicas, académicas e materiais dos campi levaram à criação de um sistema de gestão implicando que os pró-reitores, reitoria, diretores e assessorias viajem continuamente entre os polos e a cidade de Salvador (e vice-versa). Para suavizar este problema realizam-se reuniões por videoconferência. Todavia, estas não chegam para suprir as reuniões mensais presenciais com todos os diretores. $O$ transporte de materiais entre Salvador e os polos é feito semanalmente por meio do carro - o chamado "malote"- que precisa de cumprir trajetos de longa distância por estradas em condições muitas vezes precárias. Há também sérias dificuldades ao aumento da qualificação de docentes e funcionários, devido às distâncias e à falta de oportunidades académicas nos locais de origem. Mencionem-se, ainda, dificuldades relativas aos planos de carreira e os salários, além das dificuldades de comunicação e de governança entre os departamentos e a administração central, entre outras.

Ocorre, no entanto, que ao longo dos anos, apoiada nos cursos que oferece e na extensão territorial que cobre com os seus campi, a UNEB acabou por transformar parte dessas fragilidades em forças. Podemos dizer ter construído uma competência própria e única no sentido de responder, ainda que de forma algo precária e local, aos seus problemas. Tal aconteceu a partir da implantação das licenciaturas especiais (temporárias) - inicialmente em Pedagogia e, depois, também, noutras áreas, incluindo, mais recentemente, as Artes Visuais, já no âmbito da PARFOR e sobre as quais este texto incide.

Com efeito, após a implantação das licenciaturas especiais desde o final dos anos de 1990, a UNEB penetrou nos rincões da Bahia desinteressantes para os académicos da capital e negligenciados pelas políticas federais de ensino. $\mathrm{Na}$ verdade, para estas políticas tais locais não eram, na altura, cogitados como possíveis espaços para a ampliação e descentralização da oferta de graduação².

\footnotetext{
'Além de retirar totalmente a autonomia financeira, a transformação apenas nomeada das faculdades em "departamentos", o corte de vários cargos e funções e a junção de componentes e matéria num mesmo espaço académico e físico sem muita relação entre si dentro de cada departamento dificultam até hoje a gestão académica e administrativa do departamento - "faculdade". De momento, o atual governo anuncia, finalmente, a sua revogação.

${ }^{2}$ Há que considerar o enorme período durante o qual a ampliação do sistema de ensino universitário federal esteve estagnado na política dos diversos presidentes durante décadas. Essa política foi modificada no governo Lula.
} 
A oferta de ensino ao nível do terceiro ciclo fora da capital do Estado, configurada nas licenciaturas e cursos de graduação de oferta especial, delineou-se e fortaleceu-se a partir de 1999, consolidando-se como "programa intensivo de graduação", mais conhecido como Rede UNEB 2000. Criado em 1998, esse programa destinava-se a oferecer licenciaturas completas em pedagogia em diversas cidades da Bahia, respondendo a necessidades detetadas pelo governo estadual, dada a obrigatoriedade legal de existir formação superior para os docentes de toda a rede pública de ensino fundamental. Querendo ou não, o Estado da Bahia reconhecia, por isso, serem as universidades estaduais e, em especial, a UNEB, as instituições capazes de suprir essas necessidades, inclusive por já operarem no terreno3.

A UNEB estabeleceu, através das suas licenciaturas presenciais, uma relação corpórea com os alunos que estão nos confins da Bahia. Esta relação foi mais tarde desenvolvida através dos sucessivos programas destinados ao mesmo público. Entre esses está a já citada Rede UNEB 20004, o programa de formação de professores do Estado (PROESP) e, desde 2010, o plano nacional de formação de professores da educação básica, também chamado Plataforma Freire ou PARFOR.

Durante 30 anos, a UNEB foi a instituição pública de ensino superior que mais atuou no interior do Estado. Principalmente nas duas últimas décadas, a instituição tem mantido uma relação estreita com os movimentos populares, as lideranças políticas locais e as políticas de ação afirmativa. Nos municípios onde possui campi ou polos, a UNEB é mais do que uma universidade. É parte da vida das pessoas e, no dia-a-dia, articula parcerias fundamentais na comunidade para resolver questões práticas como chegadas e saídas de professores, alojamentos, estadias, alimentação e hospedagem de alunos e eventos.

A UNEB foi, por exemplo, a primeira IES do Estado da Bahia a assumir a política de quotas para afro descendentes. Um outro exemplo dessa integração nas comunidades foi o momento em que a sede da unidade de Barreiras foi tomada pelos trabalhadores sem terra, em 2011. O prédio foi ocupado e as aulas foram suspensas. Não se tratava de uma ocupação feita por estudantes, mas sim da apropriação temporária de um território institucional, levada a cabo por uma comunidade, um grupo social que entrou no polo e criou um facto político. Por que motivo os trabalhadores sem terra de Barreiras se julgaram nesse direito? Por que não tomaram outro prédio institucional? A UNEB já tinha acolhido antes membros do movimento noutras atividades. Pode dizer-se que, de algum modo, os trabalhadores assumiam aquele espaço como um território seu.

Para entender melhor esse processo, pensemos por tópicos:

- Em muitas cidades do interior da Bahia, ainda impera a aspiração a ser "médico, padre, delegado e advogado". A UNEB representa para os habitantes dos municípios onde instala os seus cursos a possibilidade de aceder a formação superior, sem necessidade de deslocação. Esta é, aliás, a sua fonte principal de capital simbólico.

\footnotetext{
${ }^{3}$ Algo que continua a ocorrer, ainda que no discurso oficial o atual governador só reconheça as universidades federais; a Secretaria de Educação acaba de assinar um convénio com a UNEB na qual assume 35.000 alunos para ensino superior no Estado da Bahia.

${ }^{4}$ A REDE UNEB 2000 formou entre 2000 e 2008 cerca de 18000 alunos e ofereceu as suas licenciaturas a cerca de 183 municípios.
} 
- Devido ao seu trabalho e ação durante esses trinta anos, a UNEB conhece profundamente os modos culturais de cada comunidade e dos seus gestores, dialogando, de forma simétrica, com as autoridades políticas e as instâncias pedagógicas formativas da educação básica nos municípios onde está sedeada. A UNEB está profundamente consciente dos traços culturais baianos e tal conhecimento permite-lhe manter-se a funcionar seguindo uma lógica que nem sempre é linear, que implica negociações complexas e delicadas.

- Por ter enfrentado, desde décadas, as dificuldades das distâncias e ter aprendido a lidar com elas, a UNEB estabelece hoje um intenso diálogo com as entidades que a tornam agente com poder de decisão e influência dentro das comunidades com as quais interage.

- Para o bem ou para o mal, a UNEB acabou por estabelecer um padrão de resultados universitários que influenciou e influencia fortemente os gestores educacionais, culturais e outros dentro dos territórios, pois a formação que oferece parte, muitas vezes, unicamente dos estudos realizados dentro dessa universidade.

Assim, o nível de integração e de colaboração, resultado da co-particiação das comunidades dos diversos territórios onde a UNEB implementou os seus cursos ao longo desses 30 anos no Estado da Bahia, é profundo. Endereça a formação dos habitantes de cada polo, cidade e localidade onde atua, mobilizando diversas parcerias estabelecidas com diferentes grupos na comunidade.

$\mathrm{Na}$ última década e meia as licenciaturas especiais da Rede UNEB fizeram a diferença na formação de terceiro ciclo na grande maioria das regiões baianas. Assim, quando a Plataforma Freire foi criada, em 2010, exigindo que as universidades criassem cursos, a UNEB respondeu com rapidez e com uma grande oferta de 125 turmas nos diversos polos e municípios. Na primeira seleção para a PARFOR, publicada em dezembro de 2009, a UNEB ofereceu, dentro dos seus campi, 63 turmas em Pedagogia, 23 em Letras, 10 em Artes, 10 em Matemática, 6 em Sociologia, 1 em Física, 1 em Química e 1 em Informática, 10 em Ciências Biológicas. Depois, foram acrescentadas, principalmente, mais turmas em Pedagogia, Letras, Sociologia e Biologia. Tal só foi possível porque a universidade já tinha instalada uma estrutura de fluxogramas e de procedimentos institucionais, tanto académicos como práticos, permitindo-lhe fazer face ao volume de professores-alunos que se matricularam, assim como a toda a movimentação administrativa daí decorrente.

Com uma quantidade de alunos quase igual à dos cursos regulares, inicialmente prevendo a existência de 8000 alunos matriculados, a PARFOR configurava-se, na prática, como uma UNEB dentro da UNEB. A implantação da PARFOR recaiu tanto sobre a equipa mais próxima, como sobre os departamentos da universidade. A experiência acumulada em ações dessa natureza permitiu que a UNEB assumisse, à época, $40 \%$ de toda a Plataforma Freire do país.

\section{A IMPLANTAÇÃo DA PLATAFORMA FEIRE NA UNEB}

O plano nacional de formação de professores da educação básica ou Plataforma Paulo Freire (PARFOR), da CAPES, é um programa federal criado durante a administração do ministro de educação Fernando Haddad, em 2009. Foi como um programa 
emergencial instituído para atender ao disposto no artigo 11, inserido no III do Decreto $n^{\circ} 6.755$, de 29 de janeiro de 2009 e implantado em regime de colaboração entre a CAPES, estados, municípios, distrito federal e as instituições de educação superior - IES (CAPES, 2015). O seu objetivo é:

Induzir e fomentar a oferta de educação superior gratuita e de qualidade para professores em exercício na rede pública de educação básica, para que estes profissionais possam obter a formação exigida pela Lei de Diretrizes e Bases da Educação Nacional - LDB e contribuam para a melhoria da qualidade da educação básica no País. (CAPES, 2015, s/p)

O processo de implantação da PARFOR começou com um convite feito pelo ministério da educação a um grupo de professores de diferentes regiões e programas do país para que, em conjunto com outros gestores, elaborassem a Plataforma Freire. A UNEB foi representada pela professora Norma Neyde, fundadora do programa Rede UNEB 2000. As primeiras reuniões foram realizadas no início de 2009. Em janeiro de 2010 a Plataforma estava implantada na UNEB. Os cursos iniciaram a 25 de janeiro, de 2010 . A CAPES assumiu, então, a responsabilidade de gerir o plano nacionalmente, tendo sido criada uma divisão específica com essa finalidade. Desde essa fase de implantação, foi necessário fazer frente a um conjunto de desafios de diversas ordens, desde a gestão de recursos financeiros e humanos e físicos, até ao desenho do plano de estudos e dos instrumentos de avaliação. Quanto à gestão, uma grande concentração de poder e responsabilidades nas mãos dos diretores de departamento, somada a uma política de comunicação interna equivocada no primeiro momento tiveram de ser contornadas com alguma criatividade e, até um certo ponto, na base de alguma contestação, como veremos mais abaixo.

Entre setembro e dezembro de 2009 os diretores de departamentos fizeram o levantamento dos cursos que poderiam oferecer a partir dos seus polos, no interior. $A$ eles caberia receber o recurso, gastá-lo, seguindo as regras da CAPES e sob o controle desta. Seria também sua atribuição - e isso é muito importante - escolher, de maneira mais ou menos democrática ${ }^{5}$, quem seriam os coordenadores de curso dentro dos seus departamentos.

Também coube aos diretores assinar um documento liberando os docentes dos seus departamentos para darem aulas na PARFOR - já que a legislação, no princípio, não permitia atribuir mais carga horária aos docentes. Esse facto concentrou poder político e académico na mão dos diretores e gerou uma corrida aos postos de docente e de coordenador local.

Um outro problema, percebido meses depois da implantação da Plataforma, foi a dificuldade em lidar com os recursos financeiros providenciados pelo governo federal e

\footnotetext{
${ }^{5}$ Alguns tentaram fazer via o conselho de unidade. Mas a maior parte indicou simplesmente os nomes de quem desejava fossem coordenadores dos cursos. Assim, também a dispensa para dar aulas - uma espécie de documento que atestava que o serviço extra não prejudicaria o trabalho no departamento - era assinada pelos mesmos. Ou seja, de alguma forma, os diretores concentravam grande poder.
} 
cuja gestão estava, por determinação da CAPES, fortemente centralizada na coordenação geral da PARFOR da UNEB. Ou seja, todos os gastos, desde a compra de materiais a equipamentos, implicava uma autorização prévia da parte da administração central. Além disso, tudo estava a ser feito pela primeira vez a grande escala. Isso significava ser obrigatório existirem, pelo menos, três meses de antecedência nos pedidos, o que implicava, portanto, o desenvolvimento de uma capacidade de previsão inédita, especialmente para a área de Artes Visuais, considerando a dificuldade em comprar materiais para cada unidade curricular.

Também a comunicação entre a administração central e os coordenadores ou diretores implicou ajustes de modo a que as formas de utilização dos recursos fossem conhecidas e compreendidas por todos. As desistências dos alunos constituíram outra das dificuldades importantes no processo. Explicam-se, sua quase totalidade, pelo não cumprimento, por parte das prefeituras locais, do compromisso firmado com a UNEB de que custeariam as passagens, estadia e alimentação dos seus professores durante os módulos do curso, bem como providenciariam substitutos para as salas de aula no período de ausências.

\section{A PARFOR de artes visuais na UNEB}

O processo de criação do curso de Artes Visuais da PARFOR seguiu, de forma geral, a mesma estratégia utilizada nos outros cursos a partir de outubro-novembro de 2009. Como ponto de partida considerou-se o currículo criado para a licenciatura de Artes Visuais do PROESP, alguns anos antes e que, por sua vez, fora adaptado do modelo do curso em pedagogia do programa Rede UNEB 2000. Essa escolha deveu-se a uma questão pragmática que consistia em oferecer, no primeiro semestre, matérias gerais (Sociologia, Filosofia, Antropologia) que poderiam ser lecionadas por docentes do quadro da instituição, ganhando-se tempo para procurar externamente outros professores para as disciplinas mais específicas.

O perfil do público-alvo matriculado era ser docente em escolas municipais ou estaduais, ministrando aulas de Artes sem ter o terceiro ciclo na área. Os professores-alunos também se comprometiam a não deixar de lecionar, a não ser nos períodos dos módulos, sendo o seu estágio docente exatamente a sua própria sala de aula. Esta é uma das características mais preponderantes desse tipo de curso: um aluno que é professor, e que, dependendo do modo como conduz o estágio, pode usar este como fonte de reflexão e campo de mudança da sua própria prática.

Em toda a Bahia, milhares de professores sem o $3^{\circ}$ grau matricularam-se por via digital na Plataforma. Os candidatos submeteram-se a uma prova de conhecimentos gerais e ortográficos mínimos. A seleção baseou-se nesta prova, pois em alguns polos, o número de interessados ultrapassava o número de vagas oferecidas: 44 alunos inscreveram-se, 32 compareceram e 29 finalizaram o curso.

A lógica de execução dos componentes curriculares obedeceu, portanto, a um formato já experimentado na Rede UNEB. Consistia em realizar um módulo presencial, 
com docentes e professores-alunos, num total de 80 horas - de domingo a domingo totalizando uma carga horária equivalente à carga horária requerida por semestre num curso regular. Esses módulos nem sempre eram marcados com muita antecedência, pois dependiam das disponibilidades das salas dos departamentos em cada campus e dos acordos entre alunos e docentes. Na prática, o currículo da PARFOR é quase igual ao do PROESP, com alterações nos tópicos especiais e ao formato dos Estágios.

Com o amadurecimento da experiência curricular que já vinha do PROESP, percebeu-se que o estágio, como era tradicionalmente realizado em pedagogia, constituía um equívoco, principalmente tratando-se de professores-alunos. Porque o aluno era, na verdade, um professor já experiente a formação serviria, sobretudo, para "desconstruir" práticas docentes viciadas, mais do que "ensinar" o aluno a ser professor.

Em 2012 realizou-se uma reunião geral entre os coordenadores locais e a direção geral de cursos. Chegou-se à conclusão de que o primeiro semestre do estágio seria um momento de discussão das questões trazidas pelos próprios professores-alunos. $\mathrm{O}$ resultado desse semestre poderia ser, assim, a elaboração de um projeto de intervenção específico dentro das suas próprias salas de aula. As intervenções, a serem efetivadas no segundo semestre, constituíram-se no estágio propriamente dito, dando-se enfase a ações ligadas à área de artes e cultura, bem como a problemas com os quais os professores - alunos se tenham enfrentado.

O terceiro semestre de estágio poderia ser ainda a aplicação desse projeto para alimentar os trabalhos de conclusão de curso (TCCs). Os formatos destes poderiam ser variados, aceitando-se a elaboração de trabalhos em equipa. Seria também desejável que contemplassem a experiência e a reflexão dos alunos sobre o estágio.

Mesmo não sendo possível mudar os componentes e os currículos no processo de execução do curso, essa parte dos TCCs na prática alterada. A instabilidade do programa e da sua execução na UNEB afrouxou os laços de controlo típicos de disciplinas, cobranças e prazos, o que permitiu experimentar novidades e revelar erros.

Como diz Duarte Jr. (2001), um currículo é sempre uma resultante política de forças e de conflitos. E se há algo de instigante no processo aqui tratado o principal diz respeito ao facto de o currículo em Artes Visuais da PARFOR UNEB, ainda que tenha sido formalmente assinado, se tenha submetido ao poder transformativo gerado pelas suas próprias dificuldades. Por isso, foi sendo feito e desfeito, subvertido e traído, a todo o tempo, pondo a nu os processos de dissecação e confronto entre forças que um currículo sempre implica, embora nem sempre mostre.

O currículo atual, conforme mencionado antes, decorre do currículo criado para - PROESP, cujo projeto político pedagógico, embora limitado quanto aos objetivos e quanto a definição das habilidades e competências, trouxe benefícios e inovações relacionadas com os componentes mais livres dos seminários, oficinas, estágios e laboratórios de Artes Visuais (LAVs). No caso destes últimos, o facto de se ter conseguido bons docentes em disciplinas que incluem pintura, desenho, fotografia, escultura e introdução ao uso de tecnologias digitais nas Artes Visuais fez também uma grande diferença nos resultados finais. 
Buscou-se por meio desses componentes, proporcionar ao professor-aluno, normalmente oriundo de cursos de magistério, uma experiência prática mínima no campo artístico concreto com os materiais e ferramentas, além de uma maior consciência do seu papel como educador em arte. As oficinas interdisciplinares e de criação, por exemplo, exigem do professor-aluno que seja ativo e defina o que precisa, ou seja que oficinas fazem sentido para si dentro no seu quotidiano como professor. A partir daí, chamava-se o docente. Na prática, muitas oficinas foram repetidas em vários campi. Em parte devido à falta de docentes e em parte devido ao nível de qualidade das propostas de oficinas e de seminários e dos docentes.

Tomemos o componente curricular oficinas interdisciplinares que, proposto para todas as licenciaturas desde 2000 , inclui um trabalho conjunto com toda a comunidade de alunos do professor-aluno nas suas próprias salas de aula. No seu formato mais bem realizado, as oficinas começam no início do semestre, discutindo-se o assunto ou temática a ser tratada nas aulas. Muitas vezes, já há projetos prontos e aplicados que interessam aos professores alunos. De todo modo, a oficina é desenhada em torno de um tema central definido na turma. Um professor orienta os subprojectos das equipas de professores-alunos que são realizados nas suas escolas de origem, envolvendo, por sua vez, os alunos dessas escolas. Cabe ao professor orientador acompanhar a preparação logística, pedagógica e imagética desses projetos.

A oficina termina com um evento especial na escola onde o professor-aluno leciona, expondo-se os resultados de todos os subprojectos, com a presença do professor orientador ou, em caso de impossibilidade deste, de um colega que o represente. A realização desses eventos implica numa fuga à rotina da escola e funciona como uma inovação e uma oxigenação para os professores que não estão no curso, dado requerer necessariamente articulações administrativas e negociações académicas com as escolas que vão sediar a oficina.

Essa prática já se realiza desde 2000 com a participação das comunidades locais, financiada inicialmente pelas prefeituras no programa Rede UNEB 2000, pelo governo do Estado no PROESP e, atualmente, pelo governo federal, na PARFOR.

A nota final das oficinas interdisciplinares é atribuída, mediante a participação nos trabalhos e as ações dos professores-alunos em sala de aula durante o semestre e no dia da culminância (cerimónia de graduação). O professor orientador deve visitar as escolas para acompanhar o processo ao longo do semestre. Pode-se pensar nesse componente como promovendo uma atividade de extensão, só que em formato de componente curricular, com culminância (cerimónia de graduação) num dia específico, com a escola aberta para toda a comunidade ver e participar, especialmente os pais e os amigos da escola. Essa é uma solução para tratar a extensão e articulá-la num lugar em que não há possibilidades de oferecer cursos de extensão, por exemplo.

Os seminários temáticos são também um componente curricular. O tema é escolhido em conjunto com os professores-alunos no início de semestre, ou proposto a partir de algum projeto já realizado noutro polo e solicitado no polo em questão. A diferença é que este componente funciona como uma aula com dinâmicas e/ou palestras 
sobre conteúdos importantes. Pode contemplar também, eventualmente, mestres da comunidade que falarão sobre um saber que lhes seja próprio. Por norma, no entanto, essa atividade tem-se transformado num lugar de palestra ou de "aula magna", com bastante dinâmica e formas de interação com a plateia, de modo a não se tornar esgotante. Normalmente os seminários são abertos à comunidade académica e à comunidade externa. Para a avaliação desse componente é suficiente que o professor-aluno assine a lista de frequência. Pode-se argumentar que não há como garantir o aproveitamento nesse caso. Mas, então, volta-se à questão já tratada acima, sobre a motivação pessoal. O controlo terá que ser forçosamente intrínseco ao sujeito aprendiz. E essa realidade é cada vez mais dominante em todos os contextos educacionais.

Finalmente, o estágio supervisionado foi planeado tendo em conta a perceção da autonomia dos sujeitos, bem como as suas perguntas e angústias enquanto professores de arte na rede pública. O formato adotado é o de projeto realizado em equipas que procuram juntar professores-alunos da mesma escola ou cidade, com duração de três meses. É orientado pelo mesmo docente que ministrou a disciplina de "fundamentos", aproximando-se, deste modo, a discussão teórica que caracteriza este último dos problemas concretos enfrentados pelos professores-alunos em sala de aula. Tal, aliado aos momentos criativos partilhados nas "oficinas interdisciplinares" produzindo resultados artísticos, surpreendentes e inovadores para aqueles contextos, assim como à progressiva aplicação, pelos professores-alunos, de novas metodologias e repertórios nas suas salas de aula, vai delineando, ao longo de todo o processo, os lugares por onde passam as mudanças pessoais e profissionais e que são parte importante na avaliação da componente. Ao contrário de outras situações, em que o supervisionado pode tender a esconder os problemas, o facto de se ter começado com as perguntas e motivações artísticas e suas lacunas encaminhou a tonalidade desses estágios para um diálogo que permeia o processo avaliativo e o supera.

Dessa forma, os seminários, assim como as oficinas e os estágios, são janelas de quebra da estrutura formal de provas escritas que não avaliam o que é preciso, oxigenadores de práticas extraordinárias dentro do contexto escolar, reinventando o "fazer" do professor e criando oportunidades para que aprendizados cooperativos ocorram. Assim, evidenciam outros tipos de competência a serem valorizadas e visibilizadas, funcionando como demonstrações e criando exemplos para realização de atividades outras que não as formais tradicionais e que ainda constrangem, pelo hábito e falta de alternativas (de formação, de material ou de instalação), o imaginário dos professores nas várias regiões.

Antes de chegarmos às conclusões deste ensaio há algumas ponderações importantes que gostaríamos de acrescentar acerca dos alunos e alunas da PARFOR de Artes Visuais. A primeira delas é a de que, via de regra, esses alunos não percebem, num primeiro momento, as suas próprias práticas criativas como culturais ou dignas de sentido ou beleza. Não as compreendem como coisas fora do seu dia a dia, como extraordinárias. Mas, um dos traços das Artes é o seu caráter de extraordinário. Assim, inicialmente, as aulas do curso de Artes eram percebidas mediante os esquemas que agregam tudo o que surge como sendo mais comum na vida de um professor: obrigação, encargo, 
possibilidade de ascensão profissional e pessoal... Assim, ao decodificar essas mesmas respostas, esse grupo repetiu os mesmos vícios, desenvolvendo atitudes que manifestaria em qualquer processo de aprendizagem realizado "de fora para dentro": reclamavam do horário e da deslocação, quando, por acaso, o coordenador conseguia um ateliê fora do espaço restrito da universidade. Também reclamavam se tivessem de esperar mais um pouco por uma operação, como secar uma massa para completar um mosaico...

O que significava isso? Não percebendo inicialmente o tipo de mudança de atitude necessária frente a uma nova aprendizagem, os alunos reagiam na base de esquemas adaptativos tradicionais, não entendendo como todo o labor que ali se desenrolava enlaçava aquilo que neles também não era valorizado, ou seja, sua própria cultura, invisível para eles. As suas escolhas temáticas, o seu trabalho em conjunto, os obstáculos surgidos e transpostos no caminho foram criando situações das quais surgia o extraordinário e, por isso, o que antes era quotidiano, começou a ser percebido como um valor.

Como diz Armindo Bião: "Repetir ações é ensaiá-las para a próxima e eminente performance do dia, até que um incidente inesperado provoque um conflito e, com isso, rompa-se o fluxo da ação cotidiana" (Bião, 2009, p. 125).

Poder-se ia acrescentar: até que se rompa o fluxo da invisibilidade da ação quotidiana para quem a pratica.

Ao perceber-se o diferente, abre-se a porta ao espetacular, ou à espetacularidade. Esta nada mais é do que o momento em que o sujeito, refletindo sobre si mesmo num estado diverso do estado psicofísico quotidiano, se compreende de outro modo e muda $^{6}$. A aprendizagem de si - e obviamente das mudanças que um curso como o da PARFOR de Artes implica para a consciência de si do professor-aluno enquanto sujeito da cultura - passa pelo estranhamento e reconhecimento de atividades que, antes entendidas como quotidianas são, a partir da formação em Artes, atravessadas por outra compreensão de vida e de cultura.

Assim, o/a professor/a aluno/a, ao lidar com artes, de forma cooperativa, buscando o aprimoramento pessoal e coletivo para o bem comum - qual seja, o da sua qualificação para o ensino de crianças e jovens - reconstrói-se - enquanto um ambiente que se move e resignifica o que faz e recebe em troca, iluminando aquilo que o sujeito passa a ser. Aqui utilizo uma imagem: como "um trem de luzes", o ambiente de criação nas artes, das práticas artísticas, da fruição de obras e de processos. A experimentação de técnicas e de materiais normalmente "privativos" das "artes", conduzida e orientada por professores que são, na sua maior parte, artistas. Trata-se da discussão dos processos de mudança e de perceção educacionais e artísticas a partir do olhar das Artes e não apenas da Pedagogia. Ou seja: qualificar para a educação na imersão dos procedimentos, processos, forma de agir, materiais e resultados do campo das Artes Visuais. Uma vivência muito diferente da do magistério tradicional, atravessada por descontroles e estruturas flexíveis de avaliação, referendadas institucionalmente.

Processos como esses mudaram todos. Aos alunos, a mim, ao coordenador local. E aí, deparando-me com esse produto, esse processo durante o qual ninguém entre

${ }^{6}$ Esse vídeo retrata bem a mudança que ocorre no aluno. No minuto $2 \min 13$ a $2 \min 43$. Retirado de http://www.webtv.uneb. $\mathrm{br} / \mathrm{p} \mathrm{p}=1793$. 
os alunos era artista, mas que, em coletivo e orientados, produziram arte de qualidade e beleza - redescubro algo que esteve sempre sob o nosso olhar. Afinal, as pirâmides tinham arquitetos que não eram autores únicos. As grades que Carybé desenhou para - MAM foram realizadas por inúmeros ferreiros. E o mural de cerâmica do DEDC I, em que cada peça tem uma incrível simplicidade de desenho - qualquer um poderia realizar uma delas - juntas, formaram um mural lindo dentro do Campus I e, provavelmente, uma das poucas produções artísticas coletivas dentro de toda a UNEB.

A possibilidade de trabalhar coletivamente sem censuras e julgamentos e a valorização do que é feito e do resultado conjunto, produziram mudanças na perceção de todos e de cada um. Reverteu a ferida de serem "alunos/as de segunda classe", reorganizou o que eles/elas avaliavam como competência. O facto de as suas produções serem divulgadas nos espaços da UNEB e, fora da sua própria turma, tornou-os/os conhecidos/as e respeitados/as pelos seus eventos e produtos, em praticamente todos os polos.

A experiência da Rede UNEB 2000 e, posteriormente, do programa de formação de professores do Estado (PROESP) e desde 2010, da PARFOR, criaram entre a UNEB e as comunidades abrangidas um laço inédito, possibilitando melhoria real na condição académica dos docentes do Estado. De facto, no processo de instalação das Licenciaturas Especiais, hoje com 15 anos, a UNEB criou encaminhamentos administrativos e pedagógicas para enfrentar problemas, tais como as insuficiências dos professores formados na rede pública de ensino quanto a competências básicas, tais como ler e redigir, elaborar cálculos ou desenvolver raciocínios investigativos.

Finalmente, resta dizer que este ensaio procurou recuperar um longo percurso em que se cruzam políticas públicas e práxis que se enfrentam mutuamente na história da UNEB e da formação de professores no Estado da Bahia, mais especificamente dos professores em artes. Desse confronto ao longo de mais de três décadas, nascem, recriam-se, reinventam-se saídas, soluções, modos de fazer que são práticas de resistência nas quais participam professores, gestores, alunos e, de um modo mais lato, toda a comunidade.

Das ausências, das falhas, das incapacidades e impossibilidades, das insuficiências é que se têm tornado possíveis os caminhos de transformação. Importa ainda dizer que as estratégias de resistência têm um forte potencial não só de ultrapassar as limitações das políticas, mas também de as transformar, tornando-as mais eficazes e efetivas. No caso dos programas de formação de professores da UNEB e desde as licenciaturas especiais até a PARFOR, a relação entre os agentes que atuam no terreno (professores, coordenadores, diretores, gestores, alunos) e as políticas tem-se configurado num equilíbrio precário, mas capaz de inspirar saídas extra quotidianas, mergulhos criativos e transformadores.

\section{REFERÊNCIAS BIBLIOGRÁFICAS}

Barros, J. M. (1993). Velhas e novas questões sobre a cultura e a identidade. Cadernos de Ciências Sociais, 3 , 1-16. 
Bião, A. (2009). Etnocenologia e a Cena Baiana. Salvador: P\&A Gráfica e Editora.

Duarte Jr., J. F. (2001). O sentido dos sentidos: A educação do sensível. Curitiba: Criar.

\section{OUTRAS REFERÊNCIAS}

CAPES, Coordenação de Aperfeiçoamento de Pessoal de Nível Superior. (2015). Plano Nacional de Formação de Professores da Educação Básica - PARFOR. Retirado de http://www.CAPES.gov.br/educacao-basica/ parfor.

Governo da Bahia. (1997). Lei 7176/97 | Lei nº 7.176 de 10 de setembro de 1997. Salvador: Governo do Estado da Bahia. Retirado de http://governo-ba.jusbrasil.com.br/legislacao/85403/lei-7176-97.

Universidade da Bahia. (2014). Programas Especiais de Graduação. Pró-Reitoria de Ensino de Graduação. Retirado de http://www.uneb.br/prograd/programas-especiais-de-graduacao/.

Universidade do Estado da Bahia. (2012). Regimento Geral da UNEB. Salvador: UNEB. Retirado de http:// www.uneb.br/files/2009/10/REGIMENTO-GERAL-DA-UNEB-2012.pdf.

\section{NOTA BIOGRÁFICA}

Isa Trigo tem Bacharelado e Formação em Psicologia pela Universidade Federal da Bahia (1981); mestrado em Artes Cénicas pela Universidade Federal da Bahia (1998) e doutoramento em Artes Cênicas - ambos pelo Programa de Pós-Graduação em Artes Cênicas - PPGAC/UFBA (2005). É professora titular da Universidade do Estado da Bahia, UNEB, atriz, encenadora e investigadora de teatro. Atualmente é coordenadora na Plataforma Freire, da CAPES, do Curso de Artes em Primeira Licenciatura, orientando nove cursos e coordenadores locais em nove municípios baianos. Coordena também a Assessoria Especial de Cultura e Artes da UNEB - ASCULT. Desenvolve pesquisa na Associação de Sambadores e Sambadoras da Bahia.

E-mail: trigo.isa2@gamil.com

Universidade Federal da Bahia, Departamento de Educação, Rua Silveira Martins, 2555, Cabula. Salvador-BA. CEP: 41.150-000, Brasil.

* Submetido: 07-12-2015

* Aceite: 11-03-2016 